\title{
Research on Virtual Property Delivery of Online Game
}

\author{
Ding Chengzhuo \\ Wuhan University of Technology \\ Wuhan, Hubei, Chinese
}

\begin{abstract}
Delivery system also needs to be adjusted correspondingly and changed in terms of the traditional delivery rules. Under the influence of Internet technology, both the meaning and mode of delivery need to be redefined. The delivery in the traditional property law refers to the fact act of transferring one's own property directly to another person's possession. Due to the intangible nature of online game virtual property, it is impossible to be directly possessed in reality just like the property, and it can only be controlled by means of the network. This paper starts with the concept of virtual property of online games and compares it with the delivery in the traditional sense. The delivery method, transaction form and transaction rules respectively show that in five different transaction modes, the ownership change of delivery presents four different forms.
\end{abstract}

\section{Keywords-Online game; Virtual property; Delivery;} Transaction

\section{OVERVIEW OF ONLINE GAME VIRTUAL PROPERTY}

\section{A. The nature of virtual property of online game}

Although the general principles of civil law has included data and network virtual property into the scope of object protection [1], However, the non-consensus concept of "virtual property" has not been explained and defined, and specific methods of operation have not been provided, leading to the identification of virtual property in practice. In recent years, there have been a lot of researches on virtual property of online games, but no consensus has been reached. The study of virtual property of online games in China is represented by li hongchen case and yu jing case.

Most scholars follow the implicit deduction method, that is, by defining the attribute of virtual property rights, they take it into a certain existing category of civil rights, and then deduce the applicable legal rules. The main viewpoints include the theory of intellectual property, the theory of property rights, the theory of creditor's rights and the theory of new property rights. Among them, the "theory of intellectual property" has been basically refuted by subsequent researchers; The "new property right theory" fails to demonstrate the "novelty" of the legal rules of virtual property compared with the existing civil rights rules, which is difficult to be adopted as a legislative scheme. Therefore, the dispute about the property of virtual property rights is mainly reflected in the discussion of the opposition between the theory of real rights and the theory of claims [2].The "theory of real rights" advocates defining virtual property rights as ownership, which is persuasive in dealing with legal disputes caused by third party infringement of virtual property, but its defects are difficult to discuss the relationship between users and operators of virtual property. For example, if users claim ownership of virtual property, operators will lose legal basis for necessary modification of virtual property data based on service system maintenance and closing the server where virtual property is located based on reasonable business reasons. Claiming ownership by operators would deprive users of the basis for claiming rights to third parties. The "creditor's right theory" is based on the contractual creditor's right between users and operators to understand virtual property rights. Therefore, there is no difficulty in defining the rights between users and operators. At this point, the solution of "creditor's rights theory" has to resort to the relatively vague tort law mechanism of "third party infringement of creditor's rights". Although both the "theory of property rights" and the "theory of creditor's rights" have provided complete plans for the construction of the rules of virtual property, they also have defects in explaining cost and system aesthetics. They are difficult to be regarded as the optimal solution, and they are hard to compete in comparison. In terms of their system effect, both of them actually distort their original definition of the property of virtual property rights to some extent. The author thinks that, the network game virtual property and the thing that defines the property law have in common, but also has the difference, the complexity of social life and the development of times feature determines the connotation of "content" will enrich and rules apply for online game virtual property related problems [3], the following basic spirit and the requirements of the traditional property law at the same time, according to the characteristics of online game virtual property to be innovative, more is in order.

\section{B. The category of virtual property of network game}

The virtual property of online games can be divided into three categories: online game account, online game virtual currency and online game virtual items.

Online game accounts. It is the main way for users to connect with the virtual game world. It is the user's agreement provided by the operator and registered with personal information and relevant information. By virtue of special procedures or requirements, users can have the relevant characters and objects, and can successfully play the game. Users must register at least one game account to enter the operation page of the game. In the normal game experience, users can get a sense of accomplishment through the game experience, experience a process of upgrading their level, establishing social relations and constantly growing, which will cost a lot of time or economic costs. Whether it is time or 
money, by processing and evolving tradable goods in the game, and reflecting huge economic benefits as the transaction expands, both the newly emerging "studio" proxy account and the second-hand account after the old players "abandon the pit" can become the trading object[4].

Online game virtual currency. It is to point to by network game management unit issue, network game user use legal money to press certain proportion direct or indirect buy, exist outside game program, store in the server with electromagnetism record way, show with specific number unit fictitious change tool. Virtual currency is a kind of virtual goods, but it has the function of "general equivalent" in the world of online games. Therefore, the virtual currency was analyzed separately[5]. The main function of virtual currency is to "" buy" "special services provided by operators on online games or online social platforms. Users can either "buy" these online services by completing tasks, using virtual currencies accumulated in games, or indirectly enjoy these services by purchasing virtual currencies with real money.

Network game virtual items, it is a game in the process of running rules allowed by the user by setting all kinds of characters, such as game skills to help them in the game to complete various tasks and work of virtual items, depending on the source of the virtual goods produced can be divided into system default virtual items and user-created virtual items. The system preset virtual items are generated according to the game program designed by the game developer. These codes are displayed by the game engine with game equipment, game props, etc., in front of the users' eyes. Its production conditions follow the preset and drop rate of game programs, such as props, materials, pets, etc. directly produced in the game. Such virtual items are the main source of virtual props in online games, because they are simple to make and convenient to trade. Type user-created virtual items is based on the system default virtual items on the basis of the players on the original processing and forming, the author thinks that this kind of users to create virtual items with intellectual property rights, such as user pinch out of his role in the game, and as in "my world" in the game players to create any specific things, and even play a role in the real world, players can decide its created on behalf of the fate of virtual goods code, and this kind of virtual items for gives the author's creativity has more trade value.

\section{COMPARISON OF VIRTUAL PROPERTY DELIVERY METHODS FOR ONLINE GAMES}

The principle of public declaration is the basic principle of property law, which is applicable to all kinds of changes of property rights with the method of legal action. Based on this principle, the real right change of movable property takes delivery as public demonstration method, while the real right change of real property takes registration as public demonstration method. The theory and practice have no objection to this. At the same time, article 115 of the property law stipulates that property includes real property and personal property. If the law stipulates that the right is the object of the real right, it can be seen that the legislator leaves room for the scope of the object of the real right. Based on the traditional principle of real right of the public, the network game virtual property as a new type of property right its public methods must be different from personal property and is different from real estate, first of all, whether it's traditional way of movables delivery or publication of the real estate registration principle has showed transfer or public action, such as personal property delivery, requirements for people must lose possession for the receiving party, in order to make the latter in exercising the fact there is no obstacle on management, especially the rapid development of science and technology today, cause the delivery way changeful, the meaning of the delivery is no longer limited to the direct transfer of possession; The concept of delivery should be adapted to the transaction needs of modern society and be expanded with the fact management as the center.

\section{A. Difference in real estate registration}

The title of this paper is "on the delivery of virtual property of online games", which excludes real estate, but it is still compared with real estate for the sake of discussion. The reasons why online game virtual property is different from real estate should include the following. First of all, in terms of the meaning of the articles, the term "delivery" is specific to movable property [6]. For example, article 23 of the property law stipulates that the establishment and transfer of movable property shall be effective at the time of delivery, unless otherwise provided by law. Second, the network game virtual property has the characteristics of general real estate: not as no body content, based on the electromagnetic records as the carrier is widely exist in the cyberspace, not has the characteristics of the location fixity realty immovability, efficient and convenient way to deliver modern society makes its liquidity and is strong, even far more than the ordinary personal property; The virtual property of online games is highly mobile, the subject is small, the object is flexible and easy to use, and it is difficult to apply the registration system on traditional real estate. Based on its own technical characteristics, the virtual property of online games presents the characteristics of reproducibility, which is also contrary to the characteristics of the uniqueness and individuality of traditional real estate. The amount of virtual property in current online games is difficult to count, which is different from the limited amount of real estate. Therefore, the real estate publicity is not applicable to the network game virtual property.

\section{B. Difference in the chattel delivery}

The term "delivery" refers to the act of transferring one's own property or the certificate of rights on behalf of property to another for possession. It can be divided into realistic delivery and fiction delivery. The latter can be divided into simple delivery, instruction delivery and possession modification. Delivery is an essential element for the change of the real right of movable property. The transfer of ownership as the meaning of possession transfer is of great legal significance, which determines the transfer time of ownership and risk. Delivery in the framework of tangible delivery is understood as the fact that the actor consciously acquires possession and loses possession. As a special property, the virtual property of online games cannot be applied to the general way of delivery. China's property law also provides for special movables, which refer to movables such as ships, aircraft and motor vehicles that can be moved and have special status. As they are mobile and do not damage value, ships, aircraft, motor vehicles and so on 
belong to the category of movable property. However, because it is used as a means of transportation and is of great value, and has distinguishing features from other things, it exists as a special movable property which is different from general movable property. Although they are special, they are still physical objects, so the delivery is also the public way of the real right change of special movable property. However, the virtual property of online games does not have its considerable value, nor is it a physical object, obviously cannot be classified into the same category.

The movables delivery specified in the traditional property law system is the core of the chattel ownership change, however, delivery system should be adapted to the economic life, with the development of the era and the popularity of Internet technology, delivery system also need to follow the rules of traditional delivery basis, according to the reality to make corresponding adjustments and changes. Under the influence of Internet technology, both the meaning and mode of delivery need to be redefined. Delivery in the traditional property law refers to the act of transferring one's possession directly to another. Due to its intangible nature, virtual property of online games cannot be directly possessed in reality, and can only be controlled by means of network. In essence, with the delivery of virtual property of online games, online game users acquire a series of electromagnetic records. For example, online game users buy and sell the game accounts, and the seller user informs the buyer user of the account information, so that the buyer user can obtain all the electromagnetic records of the account, including the virtual currency and other virtual items, at this time, the delivery is completed.

\section{ANALYSIS ON VIRTUAL PROPERTY DELIVERY RULES FOR ONLINE GAMES}

When the customer transacts directly with the user, the parties' autonomy of will shall be fully respected, and the sales contract concluded by the users of both parties may adopt any delivery method. For example, the seller's user may first give the game equipment to the buyer's user for trial, and agree on a certain trial period. When the buyer's user decides to buy the game after the expiration, the buyer's user shall be deemed to have completed the delivery when signing the sales contract by both parties. When users trade models, consignments and guarantee transactions via the built-in platform, due to the particularity of their transaction modes, they can only adopt the realistic delivery mode instead of the conceptual delivery and the artificial delivery mode. If the buyer user selects the goods to be purchased when trading on the built-in platform, the goods will be placed in the account of the buyer user after payment, and the delivery will be completed. In B2C mode, users and operators adopt the form of pseudo-delivery. The user purchases virtual currency from the operator with legal currency, and then exchanges the virtual currency for game equipment or other virtual objects [7]. At this time, the virtual currency, as a kind of debt voucher, meets the requirements of the pseudo-delivery, that is, in this transaction mode, when the user obtains the virtual currency, the operator completes the delivery.

In the transaction mode of user's own transaction mode and the transaction mode of built-in platform, the change rule of movable property right can be applied. After the buyer pays, the seller shall deliver the virtual object at the same time. When the buyer's account obtains this electromagnetic record, the delivery is completed and the right to use the virtual object will be transferred to the buyer's user.

In guarantee transaction mode, the seller users will virtual objects has transferred to the buyer, the buyer and the seller and for a period of time can be further negotiations, the buyer of the user may carry on the inspection of virtual objects, after inspection and correct confirmation after receiving, the third party platform user will give the payment to the seller, in other words, during this period, network game virtual changes in the ownership of virtual property rights is still in the state of uncertainty. In this mode, the actual delivery time of the seller's user should be when the seller transfers the virtual object to the buyer's user for possession, or when the buyer's user confirms receiving the goods and fully obtains the right to use the virtual object. In my opinion, the former should be the delivery time. The reason: first, users will virtual content transferred to the buyer when the seller has, the virtual objects by electromagnetic records have been deposited in the buyer's user account in game, under complete control of the user by the buyer, the buyer of the users of the virtual objects with full right to use, confirm the delivery of the buyer whether the user as part of the sales contract to perform the process, affect only the seller users for payment for goods, and will not affect the use of virtual objects; Secondly, when the seller user transfers the virtual object to the buyer user, the risk will be transferred accordingly. If the virtual object is lost or devalued, the buyer user shall bear the responsibility. Thus, the delivery is completed when the seller user transfers the possession of the virtual property of the network game to the buyer user. After the delivery, the ownership change of the virtual property of online games is still in an uncertain state. The ownership change is finally completed after the buyer confirms the receipt of the goods.

Under the consignment transaction mode, although the seller user has transferred the possession of the virtual object to the third party platform before the third party platform delivers the virtual object to the buyer user, it is not appropriate to assume that the goods will be delivered when the seller user transfers the possession to the platform for the first time. At this time, although the seller provides the game account and password to the third-party trading platform, the seller still has complete control over its game account. If it is still determined to deliver in this state, it is against the principle of fairness and does not meet the transaction security considerations. On the other hand, the seller's user's provision of the game account and password to the third-party trading platform shall be deemed as the performance of the trusteeship contract between the seller's user and the platform, which has nothing to do with the online game virtual property sales contract[8].Therefore, the confirmation of delivery needs to consider two aspects: first, the buyer user actually acquires the network game virtual property, that is, the electromagnetic record corresponding to the virtual property is stored in the buyer's game account; Second, the seller user is completely out of control of the virtual property of the network game. It can be seen that the delivery under this mode shall be completed when the platform 
transfers the possession of the virtual property of network games to the user of the buyer. After the delivery, the user of the buyer obtains the right to use the virtual property of network games.

B2C trading patterns in the form of an artificial delivery, therefore several trading mode with the changes in the ownership rules are different, the cognizance of this time delivery is not in network game virtual property of electromagnetic records are deposited in the buyer's game accounts shall prevail, but paid by the buyer to game operator user after legal tender, game operators to the buyer to deliver the creditor's rights certificate users that virtual currencies when delivery is completed, the buyer's user has been made for the online game virtual property of indirect possession.

\section{CONCLUSION}

The development and popularization of Internet technology has a great impact on the traditional legal system. Law is to adjust the code of conduct of social relations, and its service for the society, the social life is complex, evolving, this has led to the law, in some cases, lags behind the social existence, in the face of the status of the relevant legislation blank, if simply copy the old system, are often confused about what to do, therefore applicable to the old system of extension and is especially important for creation of the new system.

The research of this paper shows that: the delivery of virtual property in online game transactions will be affected by the transaction mode. Under five different transaction modes of subdivision, the rights change presents four different forms. At the same time, the things of the network game virtual property and the traditional property law exists similarity, network game virtual property also has its own characteristics, on the four rights after further analysis found that the flow pattern changes for the cognizance of the network game virtual property delivery and delivery should be adopted by the rules, can the application of the creative property law existing in the system of the right change, which may be out of the legislation situation of blank.

Network extends our living space, make the real world outside is a virtual network game world, at the same time also brought online game virtual property, but the network is a double-edged sword, in bring us network game enjoyment, also can bring various problems controversy, dispute properly handle needs to have a scientific and reasonable system, and scientific and reasonable system design should be based on the multiple measurements, this paper only the tip of the iceberg, for theoretical and practical circles related issues also need further research and discussion.

\section{REFERENCES}

[1] Edward A. Cawazos and Gavino Morin. Cyberspace and the law-Your Rights and Duties in the Online World [M]. The MIT Press, 1996.

[2] IDC. Analysis of E-Commerce Market in China [M]. Goldman Sachs (Asia)LLC,2000.

[3] David Kosiur. Understanding Electronic Commerce [M]. Microsoft Press, 1997.

[4] Smith. Graham J. H. Internet Law and Regulation[M]. Sweet \& Maxwell, 1995.

[5] James Grimmelmann. Virtual Worlds and Comparative Law [M]. 49N.Y.L.Seh.L.Rev,2005.

[6] Michael Chissick. Electronic Commerce: Law and Practice[M]. Sweet\& Kelaman,1999.

[7] Zhang Tingting \& Daragh Moller. Legislation Proposed to Protect Virtual Property[J]. China Internet info. CTR, 2009.

[8] Dr. Richard A. Bartle. Pitfalls of Virtual Property [M]. The Themis Group,2004. 